\title{
How go the NHS reforms?
}

\section{Despite some progress they have done little to compensate for long term NHS underfunding}

Implementing the NHS reforms has reached a critical stage. With hospitals all over Britain restricting admissions, the problems of London becoming more evident by the day, and general practice fundholders stealing a march on nonfundholders, ministers are faced with a complex set of challenges. Add to this the impending introduction of the reforms to community care and the prospect of a tight year of NHS spending in 1993-4 and you could forgive Virginia Bottomley for wishing she had a different portfolio.

In fact, the news is not all bad. As the government is quick to point out, the level of resources allocated to the NHS has been generous in the past two years, and as a result productivity has increased and the longest waiting times have fallen. Even more important have been the improvements brought about through separating the roles of purchaser and provider. Both health authorities and NHS trusts have started to use their new powers to tackle longstanding weaknesses in the delivery of services and to bring about improvements for patients.

In the case of health authorities, the contracts that have been negotiated with providers have made more explicit the way in which resources should be used. The introduction of contracts has helped to enhance the accountability of providers to purchasers and has opened up a debate about the standards of care that should be delivered. This has been reinforced by the threat that contracts will be switched to alternative providers if the standards specified by purchasers are not met.

For their part, many NHS trusts have responded to the freedoms they now have to manage their affairs, to improve the position of low paid staff, and to introduce greater flexibility into the provision of services to patients. In this way they are seeking to increase their competitiveness and enhance the attractiveness of their services to purchasers. Those involved in managing trusts may be disappointed that they have not been allowed greater financial flexibility-a point underlined by Sir John Harvey-Jones when he visited St Luke's Hospital Trust in his Troubleshooter series on television-but a start has at least been made in improving the management of hospital resources.

General practice fundholders have also shown their ability to innovate and to use resources differently. This includes providing additional services through primary care teams, negotiating for the provision of some outpatient services in practices, changing prescribing patterns to obtain better value for money, and using those hospitals that are prepared to deliver the standard of care specified by fundholders. Despite these benefits it is too early to pronounce fundholding an unqualified success.

The reality is that the scheme has so far been limited to a small number of well managed practices, which for the most part were generously funded and chosen to succeed. In these circumstances it would have been astonishing if fundholding had not produced improvements in services for patients. Only longer experience of a wider range of practices operating in a more constrained financial climate will enable a proper judgment to be made.

One of the unanticipated gains of the reforms has been the shift of emphasis to primary care. In part this has been promoted by fundholding, but more fundamentally it has been stimulated by health authorities engaging in a dialogue with general practitioners and giving greater priority to primary care as a result. At the forefront of these developments is the Dorset Health Commission, an agency that brings together the district health authority and family health services authority.

The commission's decision to allocate $£ 1$ million of its budget for hospital and community health services to support developments in primary care illustrates the imaginative approach now being adopted by managers who have broken free of a mind set concentrating on acute hospital services and have started to use their resources to respond to need and not demand.

Developments across the country are uneven, but the shape of things to come can be seen in the greater provision of minor surgery by general practitioners, the increase in health promotion work in general practice, the employment of staff such as physiotherapists and dietitians to work alongside general practitioners, the establishment of shared care arrangements for treating conditions such as diabetes and asthma, and the introduction of "treat and teach" schemes, in which specialists carry out some of their consultations in general practitioners' surgeries and develop the skills of general practitioners in the process.

Taken together, these changes suggest that the most important effect of the reforms to date has been to challenge the traditional balance of power within the NHS. The old system of planning by decibels, in which acute services won the biggest share of resources, has been brought into question. The emerging alliance between health authorities and general practitioners, and the stimulus offered by fundholders, has put hospitals under pressure and has started 
to move resources in the direction of primary care. Yet as constraints on funding begin to bite a new dynamic is becoming apparent. This involves combined action by hospital providers, who have fulfilled their contracts with a quarter of the year remaining, and general practitioners, who as a consequence are unable to obtain hospital treatment for their patients, to put pressure on health authorities to increase the resources available to acute services. Operating under budgets constrained by the government's public expenditure policies, health authorities can do little other than wait until the new financial year before they provide extra funds for hospitals. In the meantime fundholding practices can use the spare capacity that exists. As this happens equity is sacrificed as purchasing power rather than clinically diagnosed need determines which patients should be treated. It can be only a matter of time before stories of patients being denied care because of lack of resources are in the headlines. To this extent the wheel has turned full circle and the NHS is back where it was when Mrs Thatcher was so irritated by stories of bad news about health services that she announced her review of the NHS.

What this illustrates is that, notwithstanding the progress made in the past two years, the reforms in themselves have done little to compensate for the long term underfunding of the NHS. Not only that, they have also accentuated the impact of constraints on funding by encouraging purchasers to favour those hospitals that are efficient and responsive to patients. Those who gain from this process-whether in primary or secondary care-are matched by others who lose in the zero sum game that resource allocation in the NHS has become. On the principle that losers always shout louder than winners, a winter of discontent is in prospect. What price another NHS review?

CHRIS HAM

Professor,

Health Services Management Centre,

University of Birmingham,

Birmingham B15 2RT

\section{How useful is activated charcoal?}

\section{Studies have left many unanswered questions}

Charcoal will adsorb most poisons, at least to some extentthough laboratory studies suggest that lithium, iron, cyanide, and strong acids and alkalis are the exceptions. Charcoal is prepared from vegetable matter and petroleum, and "activation" creates a highly developed internal pore structure, thereby increasing the surface area from $2-4 \mathrm{~m}^{2} / \mathrm{g}$ to more than $1000 \mathrm{~m}^{2} / \mathrm{g}$. The therapeutic potential of charcoal adsorption seems high, but three questions need to be answered. Should charcoal be given indiscriminately to every patient who has swallowed a poison? Could it replace the trauma, indignity, and inefficiency of induced vomiting and gastric lavage? And which poisons can be eliminated more rapidly by repeated doses of charcoal?

Though a few reports suggest no benefit, ${ }^{1-4}$ others have shown that, when given 30 to 60 minutes later, a single dose of charcoal reduces the absorption of aminophylline, ${ }^{1}$ ampicillin, ${ }^{5}$ aspirin, ${ }^{67}$ carbamazepin, ${ }^{8}$ digoxin, ${ }^{6}$ doxepin, ${ }^{9}$ mefenamic acid, ${ }^{10}$ paracetamol, ${ }^{11}$ phenobarbitone, ${ }^{8}$ phenytoin, ${ }^{6}$ tetracycline, ${ }^{1}$ theophylline, ${ }^{12}$ and tolfenamic acid. ${ }^{4}$ All these studies, however, were done on fasting volunteers given non-toxic doses and a comparatively large dose of charcoal (usually $50 \mathrm{~g}$ ). The results are of doubtful relevance to clinical settings in which an uncertain - but usually larger-amount of drug has been taken after food and often in association with alcohol and other drugs. The lack of satisfactory studies on the use of activated charcoal in reducing drug absorption in poisoned patients is largely because the task is so difficult.

Comparative studies in volunteers have shown that activated charcoal is better than either syrup of ipecacuanha ${ }^{71314}$ or gastric lavage ${ }^{5}$ in reducing drug absorption. This conclusion has been supported by observations in patients poisoned with paracetamol. ${ }^{15}$ Nevertheless, it has not yet been shown that in these circumstances charcoal reduces the need for an antidote.

Turning to the third question, repeat doses of activated charcoal are thought to act in several ways. Firstly, the charcoal adsorbs unabsorbed poison still present in the gut. This is particularly relevant in the cases of slow release preparations such as theophylline and of drugs that are absorbed slowly because they decrease gastric motility (for example, tricyclic antidepressants). Next, charcoal adsorbs drugs that are secreted in bile, thereby preventing their enterohepatic recirculation. Thirdly, charcoal binds any drug that diffuses from the circulation into the gut lumen, thus interrupting the enteroenteric circulation. After absorption a drug will re-enter the gut by passive diffusion provided that the concentration there is lower than that in the blood. The amount diffusing depends on the concentration gradient, the intestinal surface area, the permeability of the mucosa, and blood flow. Immediate adsorption of the drug by charcoal in the lumen ensures that the concentration gradient is kept as high as possible and that diffusion continues. A few unusual drugs such as digoxin may be secreted actively by the intestinal mucosa, but this process is unlikely to contribute more than passive diffusion does to the effect of activated charcoal on drug clearance. Again much of the published evidence comes from studies in volunteers, which have shown that repeated doses of activated charcoal increased the elimination of amitriptyline, ${ }^{16}$ carbamazepine, ${ }^{8}$ dapsone, ${ }^{17}$ doxepin, ${ }^{9}$ digoxin, ${ }^{18}$ digitoxin, ${ }^{19}$ phenobarbitone, ${ }^{8}$ phenytoin, ${ }^{20}$ phenylbutazone, ${ }^{8}$ and theophylline ${ }^{21}$ but not of imipramine ${ }^{22}$ or salicylate. ${ }^{23}$ Studies in poisoned patients have confirmed these observations in the case of carbamazepine, ${ }^{24}$ dapsone, ${ }^{25}$ digoxin, ${ }^{26}$ phenobarbitone, ${ }^{27}$ phenytoin, ${ }^{28}$ and theophylline. ${ }^{29}$ There is also evidence that, contrary to findings in volunteers, activated charcoal will increase the elimination of salicylates, ${ }^{30}$ possibly because drug metabolising enzyme systems are fully saturated at the higher plasma concentrations attained in cases of acute poisoning. A beneficial effect has also been claimed in dothiepin poisoning. ${ }^{31}$

What conclusions can be drawn? Most patients coming to hospital after an overdose are not at serious risk. The challenge is to identify at an early stage those who are most at risk of developing serious complications so that appropriate treatment may be given. More information is required before gastric lavage can be abandoned completely in favour of giving activated charcoal, but a reasonable alternative to lavage would be to give $50-100 \mathrm{~g}$ of activated charcoal to adults who have taken a substantial overdose of a toxic substance no 